\title{
Transformative Learning Potentials of Trainee Health Workers in Nsukka, Enugu State, Nigeria
}

\author{
Evelyn N. Nwagu
}

\begin{abstract}
This study investigated transformative learning and the influence of learning experiences and demographic characteristics of the learners on transformative learning of trainee health workers in Nsukka, Enugu state, Nigeria. Descriptive survey design was used for the study. The instrument for data collection was a fixedchoice and open-ended questionnaire. Frequencies and ANOVA were computed. Thematic content analyses for open-ended questions were done. Participants indicated a high degree of transformative learning. Programme type, gender, age and level of study had no significant influence on the transformative learning potentials of the students. The most frequently selected learning components were field trips and presentations. Students' responses to the open-ended questions covered themes such as better understanding of health, illness and health care. The study demonstrated the importance of discussion and debate in developing critical reflection among learners.
\end{abstract}

Keywords: Transformative learning, Critical reflection, Change, Health workers, Health, Illness, Health care.

\section{Introduction}

Worldwide, the transformation and scaling up of health workers' education and training are important issues of concern. A large proportion of health workers in Nigeria and other Sub-Saharan African countries are trained in post-secondary health institutions and they form the major health workforce in health facilities in many communities in Nigeria. While training institutions for health workers in developed nations of the world are undergoing reforms to increase the competencies of health workers trained in such institutions (Stubbs, 2015; World Bank, 2018), there is a scarcity of information and research about health workers training in Sub-Saharan Africa, particularly Nigeria. Albeit, there is a need for all health professionals and health workers in all countries to be educated to mobilise knowledge, engage in critical reasoning, and practice ethical conduct so that they are competent to participate in patient and population-centred health systems as members of

Full listing of authors and contacts can be found at the end of this article. locally responsive and globally connected teams (Frenk, Chen, Bhutta, Cohen, Crisp, Evans, ...Zurayk, 2010). The training of health workers should, therefore, give rise to personal and social transformation which is one of the United Nations Educational, Scientific, and Cultural Organization's (UNESCO) five pillars of learning for sustainable development: Learning to transform oneself and society (UNESCO, 2010).

\section{Literature Review}

Transformation is an internal fundamental change in one's beliefs for action (Palinkas, 2013). It is quite different from mere change in behavior. While change uses external influences to modify actions, transformation modifies beliefs so actions become natural and thereby achieve the desired result. Change amends the past while transformation creates the future. Change and transformation could result from the learners' experiences.

Experiential learning has been described as the type of education whereby knowledge and meaning are contextualized in actual experiences (Perry, 2011). 
Meeting new and challenging experiences could lead to the uncomfortable situation described by Mezirow (1991) and could lead to a learning outcome. Mezirow stated that only through reflection, active learning, and placing ones selves in uncomfortable situations are individuals able to develop their understanding of the world and of themselves, allowing a potential change to their perspectives and frames of reference. Strange \& Gibson (2017) noted that by applying the basis of experiential learning to the potential outcomes of transformative learning, it may be possible to further direct educational programming for the better.

Experiential and transformative learning are associated with the desired goals of health workers training programmes. It is apt to use them both as frameworks to assess the transformative learning potentials of trainee health workers. Experiential learning can, thus, provide guidance in designing health worker training programmes such that they will include activities that are "more hands on."

Transformative learning theory (TLT) focuses on the processes involved in changing an individu-al's frames of reference (Stange \& Gibson, 2017). The transformative learning theory was propounded by Jack Mezirow in 1978. Mezirow asserted that adults make meaning of their experiences and that the specific social structures within which the experience takes place enable adult learners to read meaning into their experiences. Where such meanings are found to be dys-functional they change their meaning of them (Cranton, 2006; Mezirow, 1991; Taylor, 2007). The process of evaluating meaning structures starts with instrumental learning, passes through communicative learning and then transformative learning (Mezirow, $1998,2003)$. These three domains though distinct are interrelat-ed (Mezirow, 1981) and they occur through critical reflection and rational discourse (Moyer \& Sinclair, 2016). Instrumental learning occurs when the learner manipulates and controls the environment, predicts observable physical and social events, and takes appro-priate actions (Cranton \& Roy, 2003). The environment in training institution for health workers is a source of instrumental learning. Students admitted into such institutions are capable of manipulating the environment to an extent that can bring about transformative learning. Students can search out information from the Internet, interact with other students, get themselves involve in discussions and debates and also interact with clients during the training programme. Hence this study explored whether or not transformative learning occur in health workers in institutions of training for health workers. Communicative learning is born out of a need to understand others and make it easier for interlocutors to understand each other by navigating language, values, beliefs, and feelings (Cranton\& Roy, 2003; Mezirow, 1997). The learners, their teachers and the clients within such institutions have diverse values, beliefs, feelings and even languages. Interacting with each other in these institutions could bring about reflective reasoning that can trigger transformative learning.

Experiential Learning Theory (ELT) provides direction as to how we can develop the type of action-oriented experience that is likely to induce transformation. Experiential Learning involves concrete experience, reflective observation, abstract conceptualization, and active experimentation. Concrete experience refers to an actual interaction a learner will have with the environment or a particular learning event. Reflective observation provides learners the opportunity to reflect on their experiences from different perspectives. It propels the learners into the abstract conceptualization stage, where the learners integrate their reflections from their experiences into new concepts about their learning experience and make deductions about their experiences. The final stage is active experimentation where the learner takes their newly learned concepts and deductions from the abstract conceptualization phase and applies them in new learning settings. Through touching all of these bases, knowledge is constructed and learning achieved (Kolb \& Kolb, 2005). Experiential learning associated with health worker training programmes can make a considerable impact on a student's ability to understand globally complex problems (Kiely, 2004). Montrose (2002) explains that there is little understanding among providers and administrators of what exactly constitutes experiential learning and how it can be applied to improve programme structure.

Transformative learning for health workers in communities in Low- and Middle- Income Countries (LMIC) has the potential of bridging the gap in the formal health services and communities (Black et al.; WHO, 2016). The disparity in the health of individuals living in LMIC particularly rural communities raises questions as to beliefs and practices relating to health, illness and the quality of health care in such communities. Health workers training programmes have been accused of not producing competent professionals who are able to adequately positively impact the health of the people for whom they care. This lack of competence is largely a result of fragmented, outdated, and static curricula

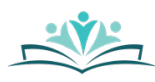


(Frenk et al, 2010). There is a need for a serious shift in the mindsets of health workers for meaningful and sustainable change to occur (Agyepong et al., 2017).

This calls for a re-examination of the health care workers' educational programme, to ensure that the curricula of health workers are able to provide the needed transformation that will help health workers assume and develop their personal, professional, and social roles. Results from such studies are essential in planning effective training methodologies and materials to improve the efficacy of knowledge-sharing of health personnel (Mbuya, Menon, Habicht, Pelto, \& Ruel, 2013; McCalman, Jongen, \& Bainbridge, 2017).

Health workers in training are adults and upon graduation, their health care job is often with adults. Adult learning involves critical thinking and reflection on what is already known in order to change and adopt a new way of doing things (Gibby, 2013). Sharing of knowledge that will produce positive result requires that health workers should believe and be convinced of the right values and practices. There is a need for health workers to drop unhealthy values and socio-cultural norms that do not allow them to actively participate in effective and health-promoting practices. Hence there is also a need for the training programme of health workers to give them adequate opportunity to reflect on their previous knowledge, values and practices with a view of transforming them positively. Such transformative learning according to Renigere (2014) will stimulate trainee health workers to learn to think independently in order to dispose of the knowledge that has at times been acquired as a result of life experience without ever thinking or asking questions.

This study, therefore, examined how the students' learning experiences have influenced their transformative learning. Transformative learning is a possible outcome of instrumental and communicative learning when modification of premises, assumptions, and deep meaning structures result in a transformation of action and behaviour (Cranton, 2006).

Therefore, presenting appropriate learning experiences to trainee health workers that will enable them to reflect on any value and meaning they may have had prior to the training may bring about transformative learning in health workers. Transformative learning encompasses a life-enhancing change (Mezirow, 2003). When learners experience transformative learning, they often become more inclusive, distinguishing, open, reflective and emotionally able to change, ultimately showing higher connectedness to the global environ- ment (Mezirow, 2003).

Educators engaged in teaching health workers should be able to identify ways of promoting students' ability to find purpose and meaning from their experiences through a variety of learning components (Bidabadi, Isfahani, Rouhollahi, \& Khalili, 2016). If health workers should develop their personal, professional and social roles, they need to develop their reasoning ability. Such reasoning hopefully will give them the opportunity to better understand the lives of other people. For instance, being able to identify the emotional states of their clients and putting themselves in other's shoes. These will help them to understand others' beliefs, feelings, experiences and intentions. Thus, they become able to think about things from others points of view (Lieberman, 2007).

Nigeria, like many other countries in Sub-Saharan Africa, faces infectious diseases, malnutrition, child and maternal mortality, emerging challenges from an increasing prevalence of chronic conditions, mental health disorders, injuries, and health problems related to climate change and environmental degradation (Agyepong, et al., 2017). Life expectancy and public health indicators remain low in Nigeria compared to that of other middle-income countries in other parts of the world. There is need to find a viable and lasting solution to bridge this gap in health status between individuals of diverse socio-economic statuses in many communities in Nigeria.

Many studies on health care services have looked at the type of services provided by health workers in low-resource communities and only a few have looked at the preparation of health workers for such service (O'Rourke, Howard-Grabman, \& Seoane, 1998; Laughlin, 2004; Matare, et al., 2015; Lamstein, et al, 2014). If efforts are made in the right directions, Nigeria has the potential to improve the health status of its population if the nation will make effective use of its available human resources (Adeloye et al., 2017). There is a need for health workers to have a change of approach in the way they view certain things and the way they act.

Health workers in most rural health facilities and in urban slums in Nigeria comprise: Community Health Extension Workers (CHEW), Junior Community Health Extension Workers (JCHEW), Nurses, Midwives and Lab Technologists. The World Health Organization (WHO) (2016) advocated that training of health workers should adopt an approach that is people-centred and inspired by progress and adapted to the country's specific needs. The basic training of these cadres of health 
workers is largely done at post-secondary training institutions, many of which are hospital based. The contributions of Community Health Workers (CHWs) are globally recognized as capable of closing the gap between formal health services and communities (Black et al., 2017; WHO, 2016). Community Health Workers are among the WHO Global Strategy for Human Resources (Maher \& Cometto, 2016) and they are considered an integral component to reach impact and equity goals (Lewin et al., 2010). Nurses and midwives have been identified to be actively involved in both hospital and community health practices (Adib-Hajbaghery, 2013). The basic laboratory services provided by laboratory technicians are very crucial for improving the potential of the Primary Health Centres (PHC) as centres providing primary health care. Inadequate training of lab technicians has been blamed for the poor laboratory service in PHC (George, 2011). The question then arises; are the training programmes in the various institutions of training of these cadres of health care workers capable of producing transformative learning among students trained in these training institutions?

\section{Purpose of the Study}

The purpose of the study was to investigate the transformative learning potentials of different cadres of trainee health personnel in Nsukka, Enugu State, Nigeria. Specifically, this study examined the influence of experiential learning and the influence demographic characteristics of participants on transformative learning outcomes.

\section{Research Questions}

1. Does transformative learning occur in trainee health workers in institutions of training of health workers?

2. How have learning experiences influenced transformative learning among students?

3. How do the demographic characteristics of age, gender, programme type and level of study influence the transformative learning of trainee health workers?

\section{Design}

\section{Methods}

The descriptive survey design was used to measure the degree of transformative learning by trainee health workers. The questionnaire was used to elicit demographic information from the students, their transformative learning as well as the experiential components of their programmes. The primary analysis tools were frequencies, means, standard deviation, percentages,
ANOVA, and thematic content analyses of open-ended questions.

\section{Data Collection}

Ethical approval for the study was granted by Bishop Shanahan Hospital ethical review board. Data were collected from students in four training institutions for health workers in the area of study. The researcher made contact with the principal of each school to obtain permission for the study. Informed consents were obtained from the participants. The questionnaire was distributed and collected on the spot to avoid omission.

\section{Participants}

The study population consisted of all trainee health workers in health training institutions in Nsukka. The total size of the population was 647 students (Students' class registers for 2017 academic session). A sample of 245 students was drawn from the five health workers' training institutions in Nsukka using the stratified random sampling technique. The stratification was done based on gender, age, level of education and course of study. A random sample proportionate to a stratum's size was taken from each stratum. The demographic characteristics of the respondents are shown in Table 1.

Table 1. Demographic characteristics of respondents

\begin{tabular}{lcc}
\hline \multicolumn{1}{c}{ Variables } & Frequency & Valid \% \\
\hline Gender & 18 & 7.3 \\
Male & 227 & 92.7 \\
Female & 245 & 100 \\
Total & & \\
Level of education & 102 & 41.6 \\
Year 1 & 78 & 31.8 \\
Year 2 & 65 & 26.5 \\
Year 3 & 245 & 100 \\
Total & & \\
Age in years & 64 & 26.3 \\
Less than 20 & 164 & 67.5 \\
21-30 & 15 & 6.2 \\
31-40 & 243 & 100 \\
Total & & \\
Course of study & 19 & 7.8 \\
Nursing & 30 & 12.2 \\
Midwifery & 52 & 21.2 \\
JCHEW & 72 & 29.4 \\
CHEW & 72 & 29.4 \\
Lab Technology & 245 & 100 \\
Total & &
\end{tabular}




\section{Instrument}

The instrument used in this study consisted of a fixed-choice and open-ended response format questionnaire. The questionnaire contained three sections. Section one was used to collect the respondents' demographic information. Section two consist of twelve items on transformative learning adapted from Strange and Gibson (2017) test of transformative learning as shown in Table 2. In order to assess whether transformative learning has occurred, Brock (2010) noted that it is important to question the learners about any change which they may have experienced in their beliefs or values. The response options for items in this section were dichotomous (yes $=1$ or no $=0$ ). Section three measured program information and experien-tial learning (see Table 3). The open-ended questions addressed the students' transformative learning experiences and their experiential learning. The open-ended questions consist of the following questions: 1) During your study in this school did you experience a situation that changed your beliefs or values about patient care? Please explain. 2) Do you think your study in this institution changed your expectations of health care in life? Please explain. 3) What was the most important thing you learned about health, illness and health care? 4) What did you learn about yourself? Please explain. 5) In what ways do you feel the program impacted your life? Please explain. 6) How long is your programme? 6) Do you feel that the length of your program is adequate to meet your goals? Please explain. 7) Did the components in your program impact your learning? How? 8) Are there any program components that were excluded that you feel would have been beneficial?

The reliability of the instrument was established by pre-testing the instrument on 20 trainee health workers in Enugu east senatorial zone who share the same characteristics with the population but are not part of the study. Section two of the instrument yielded a relatively high Cronbach's alpha of $\alpha=.80$. Two instructors from each school served as research assistants. Copies of the questionnaire were distributed to trainee health workers in the selected health training schools and the completed copies of the questionnaire were collected on the spot.

\section{Data Analysis}

Data were analyzed using IBM SPSS (Statistical Package for the Social Sciences Version 21.0). Frequencies and percentages were generated for all the variables. Homogeneity of variance was verified using the
Levene's test of homogeneity of variance. The significance of the Levene's test suggested equal variance for the four variables; gender, level of education, age, and course of study (See Table 4). ANOVA was therefore used to analyze differences in transformative learning experiences on all the four variables. Items not responded to by some respondents were treated as missing data and were excluded from the analysis. Thus, some analyses were conducted with smaller sample sizes

\section{Open-ended questions.}

The open-ended responses were analyzed to provide an in-depth evaluation of the students' experiences and transformative learning while in their training programme. Thematic analyses of the responses were done. The responses were transferred into a word file and printed out. The printout responses were reviewed and coded to identify initial categories. The open-ended questions were used as a framework for categorizing codes related to each research question. The initial set of codes were expanded and refined to better reflect the common elements that existed across the full data set. Patton (2002) asserted that this iterative style of analysis is a recognized characteristic of the qualitative research method. Patterns were identified inductively by analyzing codes associated with research questions. Further coding refinement occurred when all the codes associated with a particular open-ended question were examined for convergence. The qualitative content analysis was then used to identify themes across the codes. Examination of the response patterns across the data sets ultimately led to the emergence and identi-fication of themes. The data for transformative learning (research question one) and experiential learning (research question two) were organized as separate data sets. Response patterns were used to complement qualitative data on each research question.

\section{Results}

The responses of the students to the transformative learning questions are contained in Table 2. "I had an experience that caused me to question my ideas about health and illness behavior and health care received the highest positive responses," 94.7\% participants responded yes. Students' responses to the open-ended questions covered the following themes; better understanding of health, illness and health care; values and beliefs about patients' health care and patient's right; and expectations of healthcare roles. Changes occur 
Table 2. Students' Responses to Transformative Learning Questions

\begin{tabular}{|c|c|c|c|c|}
\hline & \multicolumn{2}{|c|}{ Yes } & \multicolumn{2}{|c|}{ No } \\
\hline & $\mathrm{f}$ & $\%$ & $\mathrm{f}$ & $\%$ \\
\hline $\begin{array}{l}\text { While in this training, I have had an experience that } \\
\text { caused me to question the way I normally act. }\end{array}$ & 209 & 86.7 & 32 & 13.3 \\
\hline $\begin{array}{l}\text { I had an experience that caused me to question my } \\
\text { ideas about health and illness behavior and health care. }\end{array}$ & 232 & 94.7 & 13 & 5.3 \\
\hline $\begin{array}{l}\text { As I questioned my ideas, I realized I still agreed with } \\
\text { my previous beliefs or role expectations. }\end{array}$ & 108 & 44.4 & 135 & 55.6 \\
\hline $\begin{array}{l}\text { As I questioned my ideas, I realized I no longer } \\
\text { agreed with my beliefs or role expectations. }\end{array}$ & 130 & 53.7 & 112 & 46.3 \\
\hline $\begin{array}{l}\text { I realized that other students also questioned } \\
\text { their beliefs. }\end{array}$ & 204 & 84.0 & 39 & 16.0 \\
\hline $\begin{array}{l}\text { I thought about acting in a different way from my } \\
\text { usual beliefs and roles. }\end{array}$ & 185 & 75.4 & 54 & 22.6 \\
\hline $\begin{array}{l}\text { I felt uncomfortable with traditional social } \\
\text { expectations. }\end{array}$ & 175 & 72.0 & 68 & 28.0 \\
\hline $\begin{array}{l}\text { I tried out new roles so that I would become more } \\
\text { comfortable or confident in them. }\end{array}$ & 217 & 88.9 & 27 & 11.1 \\
\hline $\begin{array}{l}\text { I tried to figure out a way to adopt these new } \\
\text { ways of acting. }\end{array}$ & 217 & 88.6 & 28 & 11.4 \\
\hline $\begin{array}{l}\text { I gathered the information I needed to adopt these } \\
\text { new ways of acting. }\end{array}$ & 216 & 88.5 & 28 & 11.5 \\
\hline $\begin{array}{l}\text { I began to think about reactions and feedback } \\
\text { from my new behavior. }\end{array}$ & 205 & 84.4 & 38 & 15.6 \\
\hline I took action and adopted these new ways of acting. & 200 & 82.4 & 43 & 17.6 \\
\hline
\end{tabular}

with respect to understanding health, illness and health care. Some students (18\%) expressed that they now realize that health and illness is a continuum and as such health status is not static. A better understanding of disease causation and treatment were also expressed by $47 \%$ of the students. Thirty nine students (16\%) simply answered 'yes' to the question, "During your study in this school did you experience a situation that changed your beliefs or values about patient care?" but did not provide any explanation while seven students (3\%) of the students simply answered 'no' to the question without any explanation. Myths about disease causation and treatment were dropped in $18 \%$ of the students, for instance a second-year JCHEW student stated "before I came into the school, I use to think that stroke can only be caused by evil people not knowing that sickness like high blood pressure can cause it." Thirty-six percent of the students reported that changes occurred in their values and beliefs about patients' health care and patient's rights. For instance, one student midwife said "I realized that drugs weren't all that the patients needed most times but tender loving care." With respect to patients' rights, a third-year nursing student has this to say "Initially I felt patients have no choice than to abide by the nurses' opinion always but I have come to know that patients also have rights too." Again, a CHEW student stated “...I was thinking that a patient that is under your care should follow all your commands but it is not so." Changes in expectation of healthcare roles were reported by twelve percent of the students. One student midwife said "I think I expected so much from providers (health providers) but now I realize that they are just humans capable of doing what they can at a time."

The second research question asks how learning experiences influenced transformative learning among students. Table 3 provides the data on the learning components that the students experienced in their programmes. 
Table 3. Learning components experienced by students

\begin{tabular}{llcc}
\hline S/N & Learning component & f & $\%$ \\
\hline a. & Essays & 164 & 66.9 \\
b. & Formal quizzes & 112 & 45.7 \\
c. & Field quizzes & 65 & 26.5 \\
d. & Mutiple choice & 126 & 51.4 \\
e. & Short answer exams & 72 & 29.4 \\
f. & Essay exams & 163 & 66.5 \\
g. & Open-book exams & 29 & 11.8 \\
h. & Debates & 69 & 28.2 \\
i. & Group projects & 157 & 64.1 \\
j. & Student led discussions & 202 & 82.4 \\
k. & Field lectures & 105 & 42.9 \\
l. & Field trips & 58 & 23.7 \\
m. & Presentations & 200 & 81.6 \\
n. & Others (specify) & 14 & 5 \\
\hline
\end{tabular}

The students were asked to tick from a list of learning components the ones they experienced during their training programme. The component that received the highest identification was the student-led class discussion (82.4\%), followed by the presentation (81.6\%) and experiments (71\%). Only fewer than half of the students identified the open book exams (11.8\%), field trips (23.7\%), short answer tests (29.4\%), debates (28.2\%), field lectures (42.9\%) and formal quizzes (45.7\%) as learning components in their programme. Fourteen students specified other components such as demonstrations, and ward/clinical postings. The students were also asked to comment on how the components available to their programmes impacted their learning. Their responses to this question fall under the following themes: boldness in communication, increase in understanding, acquisition of practical skills. About half of the students (48\%) commented that student-led discussions, presentations and practical experiences in the health centres impacted them the most. One final year nursing student stated "presentations have made me bold and confident to speak out." A first-year Community Health Extension Worker has this to say "group discussion improve student ability ... and make you remember all that the lecturer has taught." A second-year Junior Community Health Extension Worker believed field trip impacted her the most. She said "I learnt how to conduct delivery and give injections in my field trip." A second-year male student lab technician said "they (presentations and student-led discussions) enabled me to conquer stage fright." One midwifery student had a contrary view, she said "I don't really like group things, discussions and presentations, but I discover that group discussions help to cover more (referring to class work)."

In order to expand on the experiential aspects, students were also asked, "Are there any program components that were excluded that you feel would have been beneficial?" Ten students made suggestions that include: use of social media for students' interaction on the topics taught, inclusion of debates to sharpen understanding, and on-the-job supervisions to enhance skill acquisition.

There were no significant influence of gender, level of study, age and course of study on transformative learning at .05 level of significance (Table 4).

\section{Discussion}

The result of this study showed that transformative learning does occur in health professionals' study programme (research question one). Items one (While in this training, I have had an experience that caused me to question the way I normally act. $86.7 \%$ ) and two (I had an experience that caused me to question my ideas about health and illness behavior and health care. $94.7 \%$ ) were experienced by majority of trainee health workers. Hence their training programmes were able to engender critical reflections in the students that made them aware of their wrong assumptions and beliefs about health and illness thereby producing what Mezirow (1991) defined as perspective transformation. Mezirow (1991) identified 10 phases of perspective transformation beginning with a "disorienting dilemma" and culminating in "a reintegration into one's life on the basis of conditions directed by one's new perspective". Eighty-two point four percent of the students in this study actually took actions and adopted new ways of acting. Students' responses to open-ended questions showed that much of the changes occurred in their understanding of the causation and treatment of diseases. Students acquired new knowledge which made them drop myths and fallacies about disease causation and treatment. Belief systems were also transformed. Many of the students also expressed a change in their expectation of healthcare roles. This finding is consistent with results of similar studies among health workers that have shown different degrees of transformation among health workers with appropriate learning/teaching methods (Altobelli, 2017; Renigere, 2014). It is however important to note that true transformation takes place only when learners are able to actively take steps that acknowledge their new belief (Mezirow, 1997). The study period of three years 
Table 4. The influence of the demographic characteristics of gender, level of study, age and course of study on transformative learning (ANOVA)

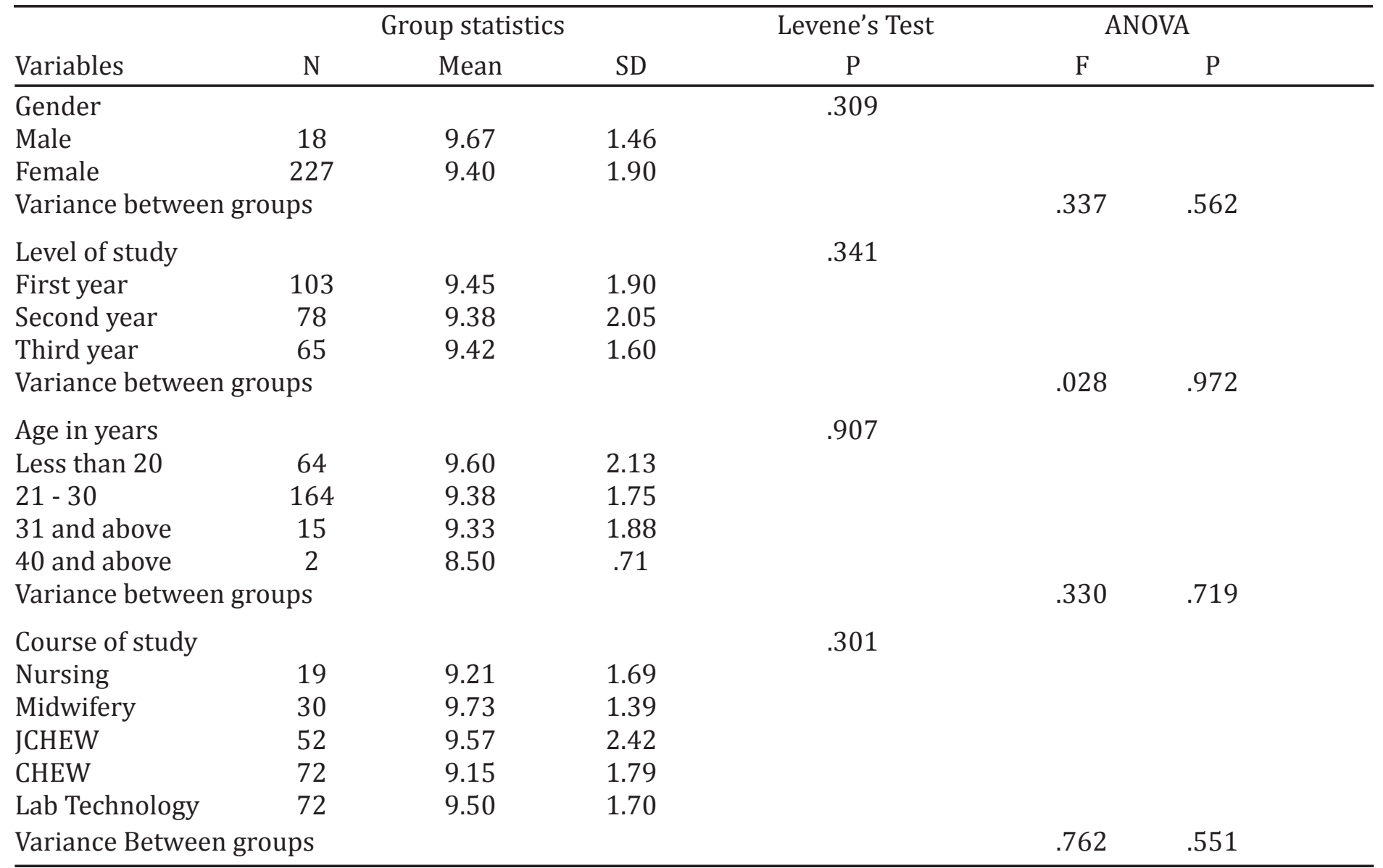

may therefore not be enough for transformation to take place.

Worthy of note is the fact that some students have no evidence of having actually experienced a transformation of their worldview and habits. Although the idea of transformation as a major, fundamental change, as opposed to minor, marginal, or incremental change, is widely agreed upon in both research and policy (Kapoor 2007; O'Brien, 2012), there is little consensus regarding the features that make change in human-environment systems "transformational," and different from "non-transformational" shifts. In fact, as some have noted (Berkhout 2013; ISSC and UNESCO, 2013; Mustelin \& Handmer 2013), the wider conceptual bases of transformation, notions of its forms, and processes have been the subject of debate. A logical question for trainee health workers educators therefore should be, "What can I do to bring a student into the realm of transformation?" Redefining the experience can make the educators to start thinking of starting the process of change and ramping it up to transformation.
The greater the difference between what came before and what took its place, the closer the individual move toward transformation (Burrus, 2017).

Moving from change to transformation may come from a simple question such as: "How can I offer my students the ability to do what they would want to do if only they knew it was possible?" In other words, rather than merely changing or even improving something, what utterly new service would health workers provide if they were aware of it and what it could do for their clients and the health system? Rather than looking to change something Burrus (2017), advocated that individuals should aim for transformation from the onset.

It is, however, worrisome that health care workers' training programmes are capable of producing transformation yet the quality of care rendered by practicing health care workers in Nigeria has been described by many as very deplorable (Ephraim-Emmanuel, Adigwe, Oyeghe, \&Ogaji 2018). The reason for this may be found in the assertion made by Mosadeghrad (2014) that factors such as the patient cooperation; leadership and 
management styles in health facilities; collaboration; available referral system; job satisfaction of the health care providers are also necessary for improved quality of health care. Addressing the training programmes of health workers alone may not produce the needed result, but rather engaging in a comprehensive restructuring of health system as a whole to improve the health care delivery. Practices such as, discriminatory behaviour and attitudes toward patients with certain forms of diseases by health workers (Reis et al., 2005) should stop.

The findings of this study have shown that trainee health workers learning experiences had influenced transformative learning in different ways (research question two). Learning experiences such as student-led discussions, presentations and practical experiences influenced students the most leading to boldness in presenting their owns view and increases in understanding and acquisition of skills. White and Nitkin (2014) observed that for transformative learning to occur, learners need to be actively engaged with experiential learning. Therefore, using appropriate learning components such as student-led discussions and presentations in teaching such contents as food habits, cultural beliefs and practices, stigmatization and discrimination and other local conditions that have negatively influenced the health of individuals and communities in Nigeria (Ojua, Ishor, \&Ndom, 2013; Olalekan, Akintunde, \& Olatunji, 2014) in teaching trainee health workers is capable of resulting in transformative learning. The trainee health workers will themselves become positively transform and will also be able to guide others to become equally transformed.

There were no significant influences of gender, level of study, age and course of study on transformative learning. While some previous studies found significant association between some demographic characteristics and transformative learning, some did not find such associations. For instance, Kumi-Yeboah (2014) in a similar study found that there were no significant association between gender, age group and programme of study and transformative learning experiences. Strange and Gibson (2017) also found that there was no statistical difference among program type and the summated transformative learning score. Brock, Florescu, and Teran (2012) however found only age and ethnicity to be the demographic variables to have significant relationship with transformative learning among class standing, semesters completed, age, prior education, gender, and ethnicity. Future studies re-examining the influence of age, gender, programme type and level of study on transformative learning of trainee health workers is therefore necessary. The present study however shows that all health workers irrespective of profession, gender, age or level of study are capable of transformative learning.

In order to expand on the experiential aspects the researcher also asked "Are there any program components that were excluded that you feel would have been beneficial?" Ten students made suggestions including: use of social media for students' interaction on the topics taught, inclusion of debates to sharpen understanding, and on-the-job supervision to enhance skill acquisition.

The students' request for the use of social media as an instructional component to enable interaction on the topics to which they were exposed in the programme is not surprising. Extending the instructional component to information technology is an innovation that has great promise of success even in the training programme of health workers. Agyepong, et al. (2017) noted that information and communications technologies and social media have been and will continue to be important enablers of Africa's transformation. Frenk et al. (2010) also noted that good professional education programmes mobilise all learning channels to their full potential noting that in many professional schools, students with handheld information technology devices are able to double-check in real time the accuracy of a lecturer's presentation.

\section{Conclusion}

This study has shown that transformative learning does occur in trainee health workers in institutions of training. The trainee health workers learning experiences have also been shown to influence their transformative learning in diverse ways. Age, gender, programme type and level of study of trainee health workers had no significant influence on their transformative learning. Therefore, needed reforms in health workers services can be achieved through appropriate learning experiences tailored to enhance critical reflection and necessary adjustment in the needed areas of their services. Discussions and debates on issues pertaining to health should be encouraged in the training programme of health workers. Professional educators are key players since they are the ones that will initiate and guide the students through the desired change. The training and education of health workers should focus less on memorising and transmitting facts and more on 
the promotion of the reasoning and communication skills that will enable the health worker to be an effective partner, facilitator, adviser, and advocate (Frenk et al., 2010). However, future studies reexamining the influence of age, gender, programme type and level of study on transformative learning of trainee health workers is suggested. Also, other factors such as patient cooperation; leadership and management styles in health facilities; collaboration; available referral system; job satisfaction of the health care providers should be investigated since these have be identified as capable of impacting the quality of health care (Mosadeghrad, 2014).

\section{References}

Adeloye, D., David, R. A., Olaogun, A. A., Auta, A., Adesokan, A., Gadanya, M., ... Iseolorunkanmi, A.(2017). Health workforce and governance: The crisis in Nigeria. Human Resources for Health, 15(32).

Adib-Hajbaghery, M. (2013). Nurses role in the community. Nursing and Midwifery Studies, 1,169170.

Agyepong, I. A., Sewankambo, N., Binagwaho, A., CollSeck, A. M., Corrah, T., Ezeh, A., ... Piot, P. (2017). The path to longer and healthier lives for all Africans by 2030: The Lancet Commission on the future of health in sub-Saharan Africa. The Lancet, 390(10114), 2803-2859. doi:org/10.1016/S01406736(17)31509-X.

Altobelli, L. C. (2017). Sharing histories - A transformative learning/teaching method to empower community health workers to support health behavior change of mothers. Human Resources for Health, 15. doi: 10.1186/s12960-0170231-2.

Berkhout, F. (2013, June). Speed, scope and depth: What counts as a socio-transformation? Paper presented at the International Conference Transformation in a Changing Climate, University of Oslo, Norway.

Bidabadi, S. N., Isfahani, N. A., Rouhollahi, A., \& Khalili, R. (2016). Effective teaching methods in higher education: Requirements and barriers. Journal of Advances in Medical Education \& Professionalism, 4(4), 170-178.

Black, R. E., Taylor, C. E., Arole, S., Bang, A., Bhutta, Z. A., Chowdhury, M. R., ... Perry, H. B. (2017). Comprehensive review of the evidence regarding the effectiveness of community-based primary health care in improving maternal, neonatal and child health: 8. summary and recommendations of the Expert Panel. Journal of Global Health, 7. doi:10.7189/jogh.07.010908.

Brock, S. E. (2010). Measuring the importance of precursor steps to transformative learning. Adult Education Quarterly, 60, 122-142.

Brock, S., Florescu, I., \&Teran, L. (2012). Tools for change: An examination of transformative learning and its precursor steps in undergraduate students. ISRN Education, 2012. doi. org/10.5402/2012/234125. 
Burrus, D. (2017). Big ideas, innovation, strategy, transformation, trends. In Change and Transformation. Burrus Research.

Cranton, P. (2006). Understanding and promoting transformative learning: A guide for educators of adults (2nd ed.). San Francisco, CA: Jossey-Bass.

Cranton, P., \& Roy, M. (2003). When the bottom falls out of the bucket: Toward a holistic perspective on transformation learning. Journal of Transformative Education, 1, 86-98.

Ephraim-Emmanuel, B. C., Adigwe A., Oyeghe, R., \&Ogaji D. S. T. (2018). Quality of health care in Nigeria: A myth or a reality. International Journal of Research in Medical Sciences, 6(9), 2875-2881.

Frenk, J., Chen, L., Bhutta, Z. A., Cohen, J., Crisp, N., Evans, T., ... Zurayk, H. (2010). Health professionals for a new century: Transforming education to strengthen health systems in an interdependent world. The Lancet, 376(9756), 1923-1958. doi:10.1016/S0140-6736(10)61854-5.

George, M. (2011). The role of basic laboratory services in strengthening primary health centres. Indian Journal of Medical Ethics, 8.

Gibby, C. (2013). Critical thinking in adult learners. Annual Review of Education, Communications, and Language Sciences, 10, 147-176.

ISSC \& UNESCO (2013). World social science report 2013: Changing global environments. Paris: OECD Publishing and UNESCO Publishing.

Kiely, R. (2004). A chameleon with a complex: Searching for transformation in international service learning. Michigan Journal of Community Service Learning, 10(2), 1-17.

Kolb, A. Y., \& Kolb, D. A. (2005). Learning style and learning spaces: Enhancing experiential learning in higher education. Academy of Management Learning \& Education, 4(2), 193-212.

Kumi-Yeboah, A. (2014). Transformative learning experiences of international graduate students from Africa. Journal of International Students, 4(2), 109-125.

Lamstein, S., Stillman, T., Koniz-Booher, P., Aakesson, A., Collaiezzi, B., Williams, T., ... Anson, M. (2014). Evidence of effective approaches to social and behavioral change communication for preventing and reducing stunting and anemia. Arlington, VA: USAID.
Laughlin, M. (2004). The care group difference: A guide to mobilizing community-based volunteer Health Educators. Arlington, VA: USAID.

Lewin, S., Munabi-Babigumira, S., Glenton, C., Daniels K., Bosch-Capblanch, X., van Wyk, B. E., ... Scheel, I. B. (2010). Lay health workers in primary and community health care for maternal and child health and the management of infectious diseases. The Cochrane DatabaseSystemic Reviews, 3, 1-173.

Lieberman, M. D. (2007). Social cognitive neuroscience: A review of core processes. Annual Review of Psychology, 58, 259-289. doi.org/10.1146/annurev. psych.58.110405.085654.

Maher, D., \&Cometto, G. (2016). Research on community-based health workers is needed to achieve the sustainable development goals. Bulletin of the World Health Organization, 94, 786.

Matare, C. R., Mduduzi, M., Mbuya, N. N., Pelto, G., Dickin., K. L., \& Stoltzfus, R. J. (2015). Assessing maternal capabilities in the SHINE trial: Highlighting a hidden link in the causal pathway to child health. Clinical Infectious Diseases, 61, 685702.

Mbuya, M. N., Menon, P., Habicht, J. P., Pelto, G. H., \& Ruel, M. T. (2013). Maternal knowledge after nutrition behavior change communication is conditional on both health workers' knowledge and knowledge-sharing efficacy in rural Haiti. The Journal of Nutrition, 143, 2022-2028.

McCalman, J., Jongen C., \& Bainbridge, R. (2017). Organisational systems' approaches to improving cultural competence in healthcare: A systematic scoping review of the literature. International Journal of Equity in Health, 16(1), 78.

Mezirow, J. (1981). A critical theory of adult learning and education. Adult Education Quarterly, 32, 3-24.

Mezirow, J. (1991). Transformative dimensions of adult learning. San Francisco, CA: Jossey-Bass.

Mezirow, J. (1997). Transformative learning: Theory to practice. New Directions for Adult and Continuing Education, 74, 5-12.

Mezirow, J. (1998). On critical reflection. Adult Education Quarterly, 48, 185-198.

Mezirow, J. (2003). Transformative learning as discourse. Journal of Transformative Education, 1, 58-63. 
Montrose, L. (2002). International study and experiential learning: The academic context. Frontiers:The Interdisciplinary Journal of Study Abroad, 8, 1-15.

Mosadeghrad, A. M. (2014). Factors influencing healthcare service quality. International Journal of Health Policy and Management, 3(2), 77-89.

Moyer, J. M., \& Sinclair A. J. (2016). Stoking the dialogue on the domains of Transformative Learning Theory: Insights from research with faith-based organizations in Kenya. Adult Education Quarterly, 66(1),39-56.

Mustelin, J., \&Handmer, J. (2013). Triggering transformation: Managing resilience or invoking real change? Proceedings of Transformation in Changing Climate. Stockholm, Sweden.

O’Rourke, K., Howard-Grabman, L., \&Seoane, G. (1998). Impact of community organization of women on perinatal outcomes in rural Bolivia. Pan American Journal of Public Health, 3, 9-14.

Ojua, T. A., Ishor, D. G., \&Ndom, F. F. (2013). African cultural practices and health implications for Nigeria rural development. International Review of Management and Business Research, 2(1), 176-183.

Olalekan, A. W., Akintunde, A. R., \& Olatunji, M. V. (2014). Perception of societal stigma and discrimination towards people living with HIV/ AIDS in Lagos, Nigeria: A qualitative study. Materia Socio-Medica, 26(3), 191-194. doi.org/10.5455/ msm.2014.26.191-194.

Palinkas J. (2013). The difference between change and transformation. CIO Insight.

Patton, M. Q. (2002). Qualitative research and evaluation methods (3rd ed.). Thousand Oaks, CA: Sage.

Perry, L. G. (2011). A naturalistic inquiry of servicelearning in New Zealand university classrooms: Determining and illuminating the influence on student engagement. (Unpublished doctoral dissertation). University of Canterbury, New Zealand.
Reis, C., Heisler, M., Amowitz, L. L., Moreland, R. S., Mafeni, J. O., Anyamele, C., \&Iacopino, V. (2005). Discriminatory attitudes and practices by health workers toward patients with HIV/AIDS in Nigeria. PLoS Medicine, 2(8). doi.org/10.1371/journal. pmed.0020246.

Renigere, R. (2014). Transformative learning in the discipline of nursing. American Journal of Educational Research, 2, 1207-1210.

Strange, H., \& Gibson, H. J. (2017). An investigation of experiential and transformative learning in study abroad programs. Frontiers: The Interdisciplinary Journal of Study Abroad, 29(1), 85-100.

Stubbs, E. (2015). Training our NHS health workers: Should the UK train more of its staff? Civitas: Institute for the Study of Civil Society.

Taylor, E. W. (2007). An update of transformative learning theory: A critical review of the empirical research (1999-2005). International Journal of Lifelong Education, 26, 173-191.

UNESCO. (2010). Teaching and learning for a sustainable future. Module 4: Reorienting education for a sustainable future. Institute for the Study of Civil Society.

White, S. K., \&Nitkin, M. R. (2014). Creating a transformational learning experience: Immersing students in an intensive interdisciplinary learning environment. International Journal for the Scholarship of Teaching and Learning, 8(2), 3. doi. org/10.20429/ijsotl.2014.080203.

World Bank. (2018). Health professionals education and training for health system reforms. Washington, DC: The World Bank.

World Health Organization. (2016). Global strategy on human resources for health: Workforce 2030. Geneva, Switzerland: World Health Organization.

\section{Author}

Evelyn N. Nwagu (evelyn.nwagu@unn.edu.ng) is a Senior Lecturer in the Department of Human Kinetics \& Health Education at the University of Nigeria Nsukka, Nsukka, Enugu State, Nigeria. 